\title{
Structural and Thermo-mechanical Evaluation of Two Engineering Thermoplastic Polymers in Contact with Ethanol Fuel from Sugarcane
}

\author{
Agmar José de Jesus Silva ${ }^{a}$, Nara Guidacci Berry, Marysilvia Ferreira da Costa ${ }^{a}$ * \\ ${ }^{a}$ Engenharia Metalúrgica e de Materiais, Universidade Federal do Rio de Janeiro - UFRJ, \\ C. P. 68505, CEP 21941-972, Rio de Janeiro, RJ, Brazil \\ ${ }^{b}$ Centro de Pesquisa e Desenvolvimento - CENPES, Petrobras, CEP 21949-900, \\ Rio de Janeiro, RJ, Brazil
}

Received: August 20, 2015; Revised: October 29, 2015; Accepted: November 20, 2015

\begin{abstract}
Special polymers have been used in the manufacture of storage structures and pipelines avoiding corrosive processes during ethanol fuel transport/storage. Therefore, this work investigated comparatively the effects of the ethanol on the physical-mechanical properties of poly (ether ether ketone) (PEEK) and polyamide 11 (PA-11) based on ageing tests. The WAXD and DSC results demonstrated slight reductions on the crystallinity degree of the aged PEEK, contrariwise to what happened with PA-11, where $X_{c}$ increased after ageing. However, the results of thermal, thermomechanical and mechanical analysis (TGA, DMTA, tensile and micro-IITs) demonstrated that PEEK is stable and no significant changes were observed in its elastic modulus $\left(E_{y} \approx 3.4 \mathrm{GPa}, E^{\prime}\right.$ and $\left.E_{i t} \approx 3.7 \mathrm{GPa}\right)$ or glass transition temperature. PA-11, conversely, was sensitive to ethanol fuel and expressive changes of its physicalmechanical properties were verified. For both materials, a reasonable correlation between crystallinity and mechanical properties was established.
\end{abstract}

Keywords: Ageing, Ethanol, Microindentation tests, Microhardness, Elastic modulus, Crystallinity

\section{Introduction}

Biofuels have emerged, as an alternative for fossil fuels in several applications. In this context, the ethanol fuel transportation as well as its storage in tanks for marketing purposes, requires structures based on materials chemically compatible with the stored substance. Ethanol production systems and storage and distribution tanks have a series of gears, parts and components such as ethanol dispenser hoses, connectors, valves of submersible pumps, membrane filters, bushings and bearings that continually come into direct contact with the fluid during their service life and need keeps their structural integrity ${ }^{1-6}$. All are frequently made of carbon steel alloys, which usually need to be coated to avoid corrosion and oxidation problems ${ }^{3-5}$. Recent studies have reported that the worldwide existing infrastructure is not fully adequate to alternative fuels as ethanol or biodiesels ${ }^{4,7}$. Furthermore, the corrosive effects of alternative fuels are not well known for this existing transport and storage structures ${ }^{4}$.

Steel tanks and dedicated pipelines offer significant advantages due to high structural resistance and low cost-effective relation if the corrosive aspects are included in the initial project. Therefore, avoiding corrosion or stress-corrosion cracking (SCC) on the metallic structures ${ }^{3-5}$, annealing or other heat treatments can be applied. In some cases, chemical inhibitors can be added to the stored or transported fuels. Additionally, another promising alternative recommended in several cases where, for instance, inhibitors are not a good

*e-mail: marysilvia@metalmat.ufrj.br option, is the use of non-metallic pipes or internal polymeric coatings in dedicated pipes and storage tanks ${ }^{7-9}$.

Engineering polymers are considered for this application due to their higher density what could reduce problems such as gas and fluid permeation. For this reason, there is currently and more than ever a great interest in developing and applying high performance polymeric materials as liners or in the manufacture of the parts themselves. Polymeric materials when employed as liners act as a protective barrier or chemical barrier. If the whole part is polymeric, its chemical inertness to the stored fluid is further intensified. In addition, high performance polymeric materials maintain a satisfactory performance in terms of key mechanical properties such as elastic modulus and yield stress over their entire service life ${ }^{6,8-10}$. However, long exposure times to the transported fluid may lead to the development of gradients of mechanical property reduction through the thickness, which may result in degradation and service failure ${ }^{8-10}$. This occurs due to the ageing of the polymer, leading to changes (increases or decreases) in its structural, mechanical and thermal properties such as tensile strength, elongation at break, hardness, elastic modulus, chemical resistance, glass transition temperature, and crystallinity ${ }^{6,11}$. The magnitude of the gradients that may appear depends mostly on the polymer, working temperature and the specific physical-chemical interactions between the polymer and the fluid. The diffusion processes and permeability may also affect the mechanical performance of the polymeric material employed ${ }^{6,8,12}$, leading to ageing and degradation of the polymer or of some product that the polymer should protect. 
Poly (ether ether ketone) (PEEK) is a semi-crystalline thermoplastic high performance engineering polymer. It has high glass transition $\left(T_{g} \approx 145^{\circ} \mathrm{C}\right)$ and melting $\left(T_{m}=340^{\circ} \mathrm{C}\right)$ temperatures and has been discussed in the literature since the $1980 \mathrm{~s}^{6,11-16}$. It can be subjected to a variety of processing routes, has high chemical resistance to many solvents and is employed in a variety of engineering applications (e.g., aerospace, automotive and chemical industries) $)^{17-22}$.

Polyamide 11 (or PA-11) is another high performance, thermoplastic and semi-crystalline engineering polymer that is widely used in industry and has a lower cost than PEEK. Its polymer chains are formed by amide and methylene groups with strong intermolecular attractions due to the hydrogen bonds that confer good mechanical, thermal and barrier properties. However, despite its versatility in terms of several technological applications, PA-11 is susceptible to chemical degradation in the presence of water (hydrolysis) and alcohols (alcoholysis), phenomena that are intensified by high temperatures (above $\left.60{ }^{\circ} \mathrm{C}\right)^{23,24}$. Chaupart et al., ${ }^{24}$ explained that there are many possible causes for this behavior, among which the two simplest are the coexistence of a depolymerization process and random chain scission, or a localized fast hydrolysis process. Nevertheless, there are no systematic studies evaluating PA-11 behavior in ethanol fuel, since this material is employed in several oil and gas application, even in contact with water, at temperatures up to $60{ }^{\circ} \mathrm{C}$, such in flexible lines for offshore oil exploration.

In this context, the present study sought to assess the comparative physical-mechanical behavior and chemical compatibility of the PEEK and PA-11, focusing the use of the PEEK in liners or in the manufacture of parts and small gears for ethanol fuel storage and transport. This is an important investigation due to increasing in the use of ethanol fuel worldwide and due to the current lack of thorough studies about the effects of the ethanol fuel on the structure of specialty polymers such as PEEK or PA-11.

To this end, PEEK and PA-11 were submitted to ageing tests in anhydrous and hydrated ethanol media at $60{ }^{\circ} \mathrm{C}$, under atmospheric pressure. The choice of the PA-11 at comparison to PEEK was made purposely because of its known and related loss of chemical resistance in environments such as pure water ${ }^{23,24}$ or oilfield water ${ }^{25}$, under the effect of temperature. In addition, some samples were aged for the same time at $60{ }^{\circ} \mathrm{C}$ (annealing with no ethanol), whereas others were aged in ethanol at room temperature $\left(23^{\circ} \mathrm{C}\right)$ for comparison. The degree of crystallinity $\left(X_{c}\right)$ of the polymers was evaluated before and after ageing, using wide-angle $\mathrm{X}$-ray diffraction (WAXD) and differential scanning calorimetry (DSC). Thermogravimetric analysis (TGA) was used to asses the thermal stability and the content of plasticizer in the materials, while dynamic mechanical thermal analysis (DMTA) was applied to study the dynamic storage modulus and glass transition temperature. The mechanical properties were evaluated by use of stress-strain curves and instrumented microindentation tests (referred here as micro-IITs), and the elastic modulus values were compared with those obtained from DMTA.

\section{Experimental Methodology}

\subsection{Materials preparation}

Commercial grade semi-crystalline PEEK (450G), manufactured by Victrex through standard injection molding according to ASTM D $638^{26}$ (Type I dogbone-shaped) was used. Plasticized PA-11 (commercial grade produced by Arkema) was supplied in pellets and processed through compression molding (six tons of pressure at $220^{\circ} \mathrm{C}$ for $5 \mathrm{~min}$ in the melting, following by a cooling at $80^{\circ} \mathrm{C}$ for $10 \mathrm{~min}$ ). Type I dogbone-shaped test specimens were also obtained. The same PEEK and PA-11 specimens were machined to prepare rectangular pieces $(30 \times 20 \times 3 \mathrm{~mm})$, which were used in the micro-IITs. Similarly, bars with dimensions of $(50 \times 10 \times 3 \mathrm{~mm})$ were produced to use in the DMTA analysis as per ASTM D $5023^{27}$.

\subsection{Ageing tests}

PEEK and PA-11 ageing tests in anhydrous and hydrated ethanol were conducted over 1 and 3 months in thermal baths containing water at $60^{\circ} \mathrm{C}$ and over 1 and 3 months at room temperature $\left(23^{\circ} \mathrm{C}\right)$, both situations under atmospheric pressure. The ageing tests were carried in accordance with the standard ISO $175^{28}$. The polymers were placed in cylindrical glass bottles of $1 \mathrm{~L}$ and with sealing caps to prevent the entry of liquids or exit of volatiles. The polymers were kept upright and separated inside the bottles. For the annealing experiments, the polymer samples were placed into a hot-air oven at $60{ }^{\circ} \mathrm{C}$ during the same ageing times. The specifications of the sugarcane ethanol are $94 \% \mathrm{v} / \mathrm{v}$ (hydrated ethanol) and 99.3\% v/v (anhydrous ethanol), both acquired from CENPES/Petrobras.

\subsection{Characterization methods}

DMTA analysis was carried out for determination of the glass transition temperature $\left(T_{g}\right)$ and dynamic storage modulus $\left(E^{\prime}\right)$ of the PEEK and PA-11. The measurements were made in the three-point-bending mode in a dynamic mechanical analyzer (DMTA 242C, Netzsch Co.). The dynamic load and the amplitude were $4 \mathrm{~N}$ and $60 \mu \mathrm{m}$, respectively. The scanning range was from 0 to $250{ }^{\circ} \mathrm{C}$ for PEEK and -120 to $110^{\circ} \mathrm{C}$ for PA- 11 at a heating rate of $2{ }^{\circ} \mathrm{C} \mathrm{min}-1$ and a frequency of $1 \mathrm{~Hz}$, under a nitrogen atmosphere.

The degree of crystallinity $\left(X_{c}\right)$ of the polymers were assessed by X-ray diffraction using a Shimadzu diffractometer operated with $\mathrm{CuK} \alpha$ radiation $(\lambda=0.1542 \mathrm{~nm})$ for $2 \theta$ values from 5 to $80^{\circ} . X_{c}$ integration and calculations were performed according to well-established procedures in the literature ${ }^{13,29-31}$.

$X_{c}$ was also calculated from DSC. The curves were obtained in a Q 8000 apparatus (Perkin Elmer) under a nitrogen atmosphere. The temperature range was from 25 to $400^{\circ} \mathrm{C}$ for PEEK and 25 to $250^{\circ} \mathrm{C}$ for PA-11, both with a $10{ }^{\circ} \mathrm{C} \mathrm{min}-1$ heating rate. The degrees of crystallinity were obtained from DSC analyses according to literature procedures ${ }^{32}$, using $\Delta H_{f}^{0}$ (enthalpy of fusion of $100 \%$ crystalline polymer) tabulated as 130 and $226 \mathrm{~J} \mathrm{~g}^{-1}$ for PEEK ${ }^{11,16}$ and PA-11 ${ }^{31}$, respectively.

The thermal stability of the PEEK and PA-11 was analyzed using TGA (Q500, TA Instruments). Approximately $15 \mathrm{mg}$ of each sample was heated from 25 to $700{ }^{\circ} \mathrm{C}$ at a rate of $10{ }^{\circ} \mathrm{C} \mathrm{min}{ }^{-1}$. The maximum temperature of the weight loss 
curves was taken as the decomposition temperature $\left(T_{d}\right)$ of the samples.

Tensile tests were performed in an Instron model 5567 universal testing machine with a crosshead speed of $50 \mathrm{~mm} \mathrm{~min}^{-1}$ and using an optical extensometer (AVE) for measuring deformation. The elastic modulus (or Young's modulus, $E_{y}$ ) was obtained from linear regressions in low deformations in the stress-strain curves, and the yield stress $\left(\sigma_{y}\right)$ was directly read from the curves.

Instrumented microindentation tests (micro-IITs) were carried out in a microindentation tester (MHT) from CSM Instruments using a three-side pyramidal Berkovich indenter tip and following the methodology described by Oliver and Pharr ${ }^{33-35}$. The contact load was defined as $10 \mathrm{mN}$, and maximum loads of 210,310 and $410 \mathrm{mN}$, with a holding time of 200 seconds, were applied, scanning different regions of the sample surface. The holding time at the maximum loading is essential to ensure reduction of creep effects (the so called "nose effect") ${ }^{33-35}$. The loading and unloading rates were $200 \mathrm{mN} \mathrm{min}^{-1}$. The micro-IITs produced mean values of $\mu-\mathrm{HB}, E_{i t}$ and maximum depth indentations $\left(h_{\max }\right)$ for the aged and unaged PEEK and PA-11 samples.

The mechanical properties obtained from stress-strain curves and micro-IITs were evaluated using statistical Student's t-tests with a confidence level $(1-\alpha)$ of $95 \%$, i.e., the differences were considered statistically significant for $p$-values below 0.05 , as described by Montgomery et al. ${ }^{36}$. Furthermore, the mean results obtained were reported as mean followed by standard deviations and coefficients of variation, and presented as mean $\pm \mathrm{SD}(\mathrm{CV})$. All statistical analyzes were performed using MS Excel (Microsoft).

\section{Results and Discussion}

\subsection{Dynamic mechanical thermal properties}

The curves of dynamic storage modulus for the unaged PEEK and PA-11 are shown in Figures 1 and 2, respectively. These curves clearly indicate the difference in the mechanical behavior of the two materials. PEEK is a much more rigid polymer over the whole temperature range evaluated. Figures 1 and 2 show that the $E$ ' values at $23{ }^{\circ} \mathrm{C}$ of the unaged materials are 3.7 GPa for PEEK and 472.7 MPa for PA-11, almost a degree of magnitude lower.

The main chain relaxation of the PEEK, taken at the maximum of $\tan \delta$, occurs at $165.5^{\circ} \mathrm{C}$, as shown in Figure 3 , similar to values reported in the literature ${ }^{6,11,16}$. This high relaxation temperature for the PEEK polymeric structure is associated with the rigid segments of its backbone, as reported by Yuan et al. ${ }^{16}$ and White et al. ${ }^{20}$. On the other hand, the flexible chains of the PA-11 can explain its $T_{g}$ value of $13.6{ }^{\circ} \mathrm{C}$ (Figure 3 ), similar to values reported by Chaupart and $\mathrm{Serpe}^{23}$, and is associated with the long segments between the amide groups and the significant amount of plasticizer present in this particular grade. It is well known that plasticizers increase the chain mobility by disrupting the $\mathrm{H}$-bonding network present in polyamides ${ }^{23}$. PA-11 also has a secondary or $\beta$ transition that can be seen in Figure 3 at approximately $-80^{\circ} \mathrm{C}$ that has been associated with segmental motions involving adjacent nonbonded amide groups with other amide groups on nearby chains ${ }^{23}$.
Figure 4 shows the $T_{g}$ values of the PEEK and PA-11 as obtained from the maximum of the $\tan \delta$. It can be observed that PEEK's $T_{g}$ is basically insensitive to fluid contact in the conditions evaluated (Figure 4b), as expected due to its chemical resistance, remaining around $165^{\circ} \mathrm{C}$ before and after ageing. Furthermore, the low temperature employed $\left(60^{\circ} \mathrm{C}\right)$ was not sufficient to modify its crystallinity or favor ethanol diffusion. A more detailed analysis on the crystallinity degree as a function of the ageing time/fluid will be shown later on.

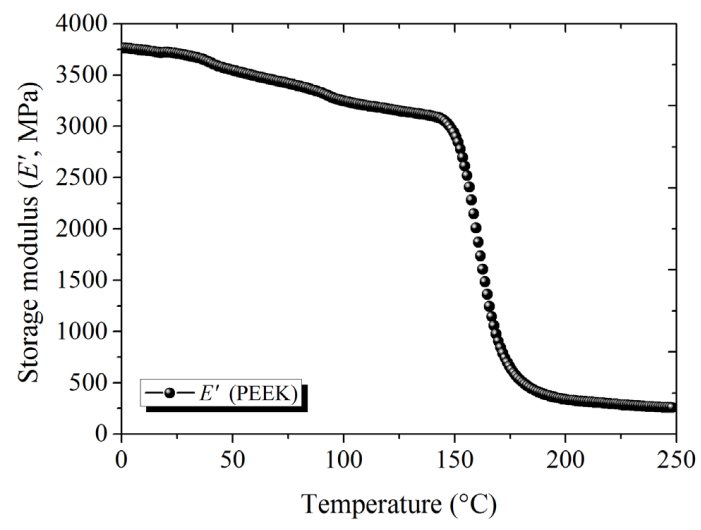

Figure 1. Storage modulus of the unaged PEEK at a frequency of $1 \mathrm{~Hz}$.

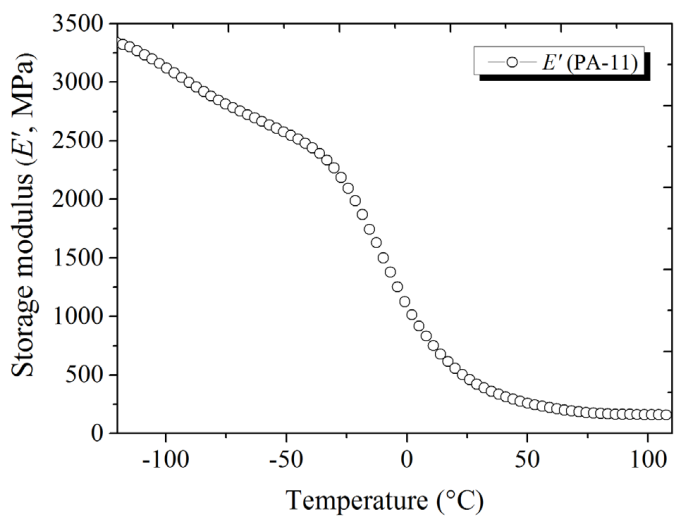

Figure 2. Storage modulus of the unaged PA-11 at a frequency of $1 \mathrm{~Hz}$.

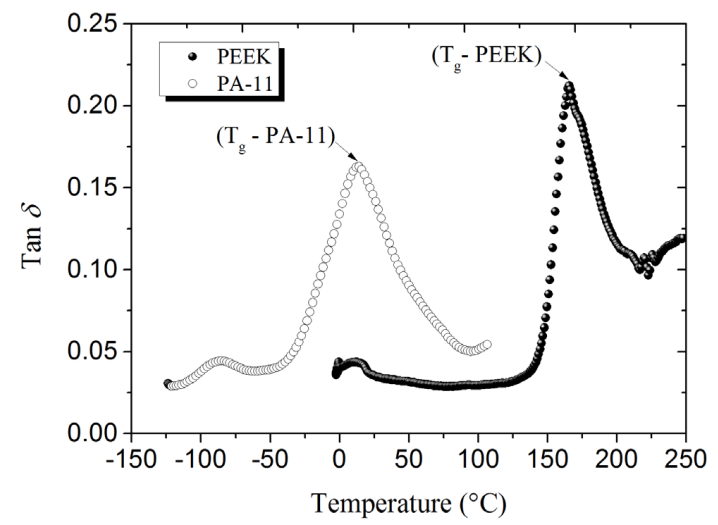

Figure 3. Tan $\delta$ values of the unaged PEEK and PA-11 at a frequency of $1 \mathrm{~Hz}$. 
On the other hand, the $T_{g}$ values of the PA-11 considerably decreased as a function of the ageing time in anhydrous and hydrated ethanol, indicating a strong sensitivity of the PA-11 to both type of alcohols, as shown in Figure 4a. After 3 months ageing, the $T_{g}$ was reduced from $13.6{ }^{\circ} \mathrm{C}$ to $-28.7{ }^{\circ} \mathrm{C}$ and $-16.5^{\circ} \mathrm{C}$ for anhydrous and hydrated ethanol, respectively. The $T_{g}$ reduction is attributed to the partial hydrolysis caused by the presence of water in the fluids, although this reaction is more drastic at temperatures higher than $80^{\circ} \mathrm{C}^{24}$, as well as a possible plasticizing effect exercised by ethanol absorbed and accommodated inside of the free volume of the polymeric chains of the PA-11 amorphous phase.

In Figures 5 and 6, the $E$ ' values of the PEEK and PA-11 are shown, respectively. The $E$ ' of the PEEK is basically constant as a function of the ageing time, ranging between 3.6 - 3.7 GPa. The PA-11, on the other hand, had a stronger reduction of its storage elastic modulus as a function of the ageing time, in both type of alcohols. At $60{ }^{\circ} \mathrm{C}$, the $E$ ' of the PA- 11 was reduced by $37.8 \%$ and $8.6 \%$ after ageing for 1 month, and after 3 months, the reductions were $50.1 \%$ and $43.2 \%$ for anhydrous and hydrated ethanol, respectively. It is interesting to note that, although the amount of water in the anhydrous ethanol was only $0.7 \%$, this fluid was more aggressive to PA-11. Polyamides are known to suffer hydrolysis at critical temperatures ${ }^{24}$, and this reaction happens even in the presence of very small amounts of water. Therefore, a similar behavior in both fluids was expected if hydrolysis was the main ageing mechanism. The results indicate that although hydrolysis may occur, the ethanol is also harmful to the material and contributes to the ageing mechanism. It is also believed that the plasticizer is extracted by a migration/diffusion process, and simultaneously, the material swells through the absorption of ethanol. This culminates in an increase in the total free volume, leading to an increase in the chain mobility, resulting in easier movement of the chains and lowering the $T_{g}$ and storage modulus of the aged materials relative to the unaged. This hypothesis was well supported through of an evaluation of the degree of swelling of the PA-11, which can be found in subsection 3.4.

\subsection{Crystallinity}

The diffractograms of the PEEK and PA-11 unaged and aged in anhydrous and hydrated ethanol at temperature of $60{ }^{\circ} \mathrm{C}$ for 1 and 3 months are supplied as Supplementary material (Appendix A). In these diffractograms, PEEK presents four main crystalline peaks at $2 \theta=18.7^{\circ}, 20.8^{\circ}$, $22.5^{\circ}$ and $28.7^{\circ}$, which, according to Nguyen and Ishida ${ }^{11}$ and Lai et al. ${ }^{37}$ correspond to the crystalline planes (110), (111), (200) and (211) of an orthorhombic unit cell. The PA-11 diffractogram presents major peaks at $2 \theta=7.3^{\circ}, 19.9^{\circ}$ and $23.0^{\circ}$, characteristic of the $(001),(100)$ and $(010,110)$ planes, respectively, of a triclinic unit cell, as proposed by Chaupart and Serpe ${ }^{23}$, Jolly et al. ${ }^{38}$ and Zhang et al. ${ }^{39}$.

Table 1 shows the PEEK and PA-11 degrees of crystallinity for the unaged polymers, the polymers aged for 1 and 3 months in anhydrous and hydrated ethanol at 60 and $23{ }^{\circ} \mathrm{C}$, and the polymers aged in hot-air $\left(60^{\circ} \mathrm{C}\right) . X_{c}$ values obtained from the PEEK and PA-11 diffractograms were compared with the values obtained from DSC (thermograms not shown). The enthalpy of fusion $\left(\Delta H_{f}\right)$ of the first heating curve for each test conducted was considered.

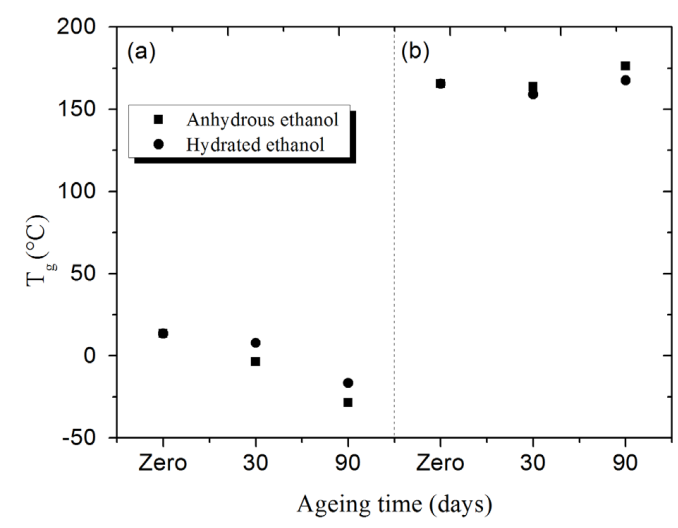

Figure 4. Variations of $T_{g}$ of the PA-11 (a) and PEEK (b) unaged and aged in anhydrous and hydrated ethanol at $60{ }^{\circ} \mathrm{C}$.

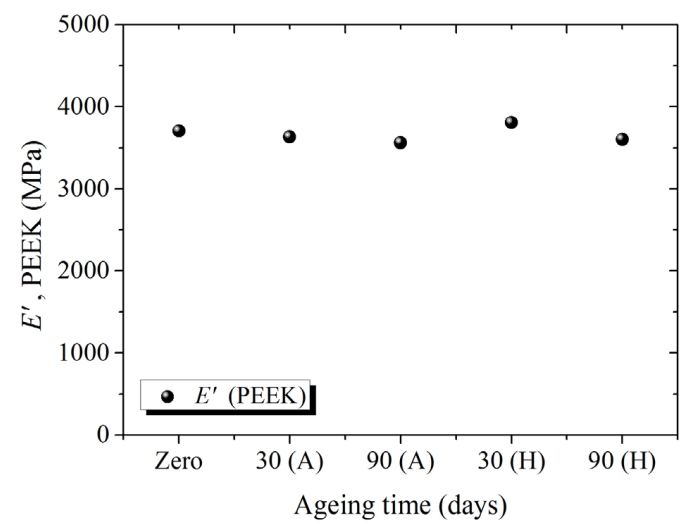

Figure 5. Variations of the storage modulus $\left(E^{\prime}\right)$ of the PEEK unaged and aged in anhydrous (A) and hydrated $(\mathrm{H})$ ethanol at $60^{\circ} \mathrm{C}$.

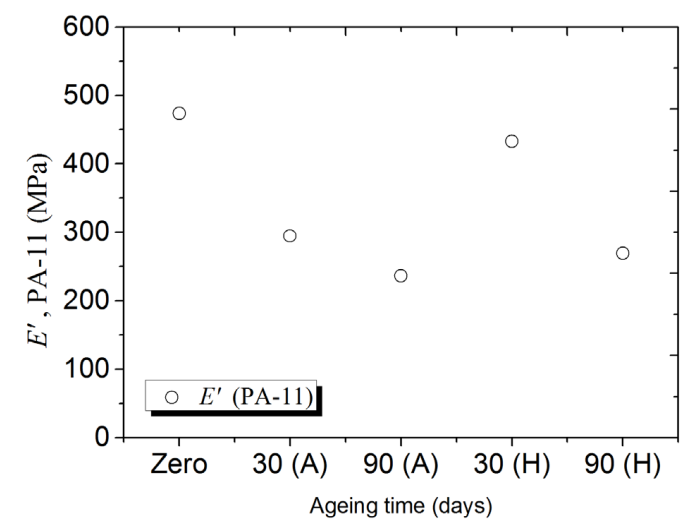

Figure 6. Variations of the storage modulus ( $\left.E^{\prime}\right)$ of the PA-11 unaged and aged in anhydrous $(\mathrm{A})$ and hydrated $(\mathrm{H})$ ethanol at $60^{\circ} \mathrm{C}$.

Although the results of WAXD were not conclusive about the changes in the degree of crystallinity of the aged PEEK (lack of a well-defined tendency of $X_{c}$ ), it can be noted that the mostly of the aged samples had a slight reduction in their $X_{c}$ values relative to the unaged PEEK, in both temperatures evaluated, as shown in Table 1. Meanwhile, the DSC results for the unaged PEEK showed a crystallinity 
Table 1. Degrees of crystallinity $\left(X_{c}\right)$ of the PEEK and PA-11 obtained from X-ray diffractograms compared with $X_{c}$ values obtained from DSC (curves of the $1^{\text {st }}$ heating scan).

\begin{tabular}{|c|c|c|c|c|c|}
\hline Material & $\begin{array}{l}\text { Experimental } \\
\text { conditions }\end{array}$ & Ageing time & $X_{c}(\%)$ - WAXD & $\Delta \mathbf{H}_{\mathrm{f}}\left(\mathbf{J} / \mathbf{g}^{-1}\right)$ & $X_{c}(\%)-D S C$ \\
\hline \multirow{7}{*}{ PEEK } & Unaged & Zero & 35.6 & 38.5 & 29.6 \\
\hline & Anhydrous & 1 month & $(32.2)^{(\mathrm{a})}(33.2)^{(\mathrm{b})}$ & $(37.1)^{(a)}(34.2)^{(b)}$ & $(28.5)^{(\mathrm{a})}(26.3)^{(\mathrm{b})}$ \\
\hline & Anhydrous & 3 months & $(35.6)^{(\mathrm{a})}(33.6)^{(\mathrm{b})}$ & $(35.9)^{(a)}(35.7)^{(b)}$ & $(27.6)^{(\mathrm{a})}(27.0)^{(\mathrm{b})}$ \\
\hline & Hydrated & 1 month & $(35.1)^{(\mathrm{a})}(34.7)^{(\mathrm{b})}$ & $(35.8)^{(a)}(33.6)^{(b)}$ & $(27.5)^{(\mathrm{a})}(26.0)^{(\mathrm{b})}$ \\
\hline & Hydrated & 3 months & $(32.3)^{(\mathrm{a})}(33.9)^{(\mathrm{b})}$ & $(34.7)^{(a)}(32.6)^{(b)}$ & $(26.7)^{(\mathrm{a})}(25.0)^{(\mathrm{b})}$ \\
\hline & Hot-air & 1 month & $(35.0)^{(\mathrm{c})}$ & $(38.1)^{(\mathrm{c})}$ & $(29.3)^{(\mathrm{c})}$ \\
\hline & Hot-air & 3 months & $(35.3)^{(\mathrm{c})}$ & $(37.5)^{(\mathrm{c})}$ & $(28.8)^{(\mathrm{c})}$ \\
\hline Material & $\begin{array}{l}\text { Experimental } \\
\text { conditions }\end{array}$ & Ageing time & $X_{c}(\%)$ - WAXD & $\Delta \mathbf{H}_{\mathrm{f}}\left(\mathrm{J} / \mathrm{g}^{-1}\right)$ & $\mathrm{X}_{\mathrm{c}}(\%)-\mathrm{DSC}$ \\
\hline \multirow{7}{*}{ PA-11 } & Unaged & Zero & 23.5 & 36.2 & 16.0 \\
\hline & Anhydrous & 1 month & $(24.3)^{(\mathrm{a})}(25.8)^{(\mathrm{b})}$ & $(52.7)^{(a)}(47.2)^{(b)}$ & $(23.3)^{(\mathrm{a})}(20.9)^{(\mathrm{b})}$ \\
\hline & Anhydrous & 3 months & $(25.6)^{(\mathrm{a})}(26.8)^{(\mathrm{b})}$ & $(49.5)^{(a)}(47.6)^{(b)}$ & $(21.9)^{(\mathrm{a})}(21.1)^{(\mathrm{b})}$ \\
\hline & Hydrated & 1 month & $(26.0)^{(\mathrm{a})}(25.7)^{(\mathrm{b})}$ & $(48.2)^{(a)}(47.0)^{(b)}$ & $(21.3)^{(\mathrm{a})}(20.8)^{(\mathrm{b})}$ \\
\hline & Hydrated & 3 months & $(26.2)^{(\mathrm{a})}(24.7)^{(\mathrm{b})}$ & $(48.1)^{(\mathrm{a})}(48.3)^{(\mathrm{b})}$ & $(21.3)^{(\mathrm{a})}(21.4)^{(\mathrm{b})}$ \\
\hline & Hot-air & 1 month & $(29.8)^{(\mathrm{c})}$ & $(41.1)^{(\mathrm{c})}$ & $(18.2)^{(\mathrm{c})}$ \\
\hline & Hot-air & 3 months & $(29.1)^{(\mathrm{c})}$ & $(49.7)^{(\mathrm{c})}$ & $(21.9)^{(\mathrm{c})}$ \\
\hline
\end{tabular}

Materials ageing conditions: ${ }^{(a)}$ Ethanol fuel at $60{ }^{\circ} \mathrm{C}$. ${ }^{(b)}$ Ethanol fuel at $23{ }^{\circ} \mathrm{C}$. ${ }^{(c)}$ Hot-air $\left(60{ }^{\circ} \mathrm{C}\right)$.

of approximately $29 \%$ and a melting point $\left(T_{m}\right)$ of $339.7^{\circ} \mathrm{C}$, whereas the materials aged at $60^{\circ} \mathrm{C}$ presented crystallinity reductions of approximately $3.7 \%$ and $7.1 \%$ for PEEK aged over 1 month in anhydrous and hydrated ethanol, respectively. When PEEK was aged over 3 months in anhydrous and hydrated ethanol, the $X_{c}$ reductions were $6.7 \%$ and $9.8 \%$, respectively. Taken together, the DSC and WAXD results suggest a plasticizing effect of the ethanol on the PEEK, which might have been the cause of the crystallinity reduction in both types of ethanol. Nevertheless, only slight changes in the $T_{m}$ values were observed, as they remained in the range of $338-340{ }^{\circ} \mathrm{C}$. This apparent crystallinity reduction can explain an intensity reduction of the PEEK characteristic diffraction peaks that sometimes occurred (shown in the Supplementary material) (Appendix A), although it did not cause any position change or the emergence of new peaks, indicating that the orthorhombic unit cell was preserved. When PEEK was aged at $23{ }^{\circ} \mathrm{C}$ under the same conditions, similar reductions of $X_{c}$ were obtained. On the other hand, samples aged purely in hot-air $\left(60^{\circ} \mathrm{C}\right)$ did not show significant changes in $X_{c}$ and $T_{m}$, indicating that the changes observed are due to the ethanol and not to temperature alone.

Unaged PA-11 presented a low crystallinity value (approximately 16\%, as measured by DSC) (Table 1), which is related to the presence of plasticizers in its polymer chain and the employed processing technique (compression molding) (23,25. $^{2}$. In the unaged condition, the complete fusion of the PA-11 occurred at $T_{m}=180.8{ }^{\circ} \mathrm{C}$. The crystallinity modification observed for PA-11 caused by ageing was opposite to that of PEEK, i.e., PA-11 experienced an increase in the degree of crystallinity in the samples aged in anhydrous and hydrated ethanol at 60 and $23{ }^{\circ} \mathrm{C}$ compared to the unaged material (Table 1). The $X_{c}$ increases in the materials aged for 1 month at 60 and $23{ }^{\circ} \mathrm{C}$, as obtained from DSC, were approximately $45.6 \%$ and $30.6 \%$ (in anhydrous ethanol) and $33.1 \%$ and
$30.0 \%$ (in hydrated ethanol), respectively. In the material aged over 3 months in anhydrous and hydrated ethanol, the $X_{c}$ increases were $36.8 \%$ and $31.9 \%$ (in anhydrous ethanol) and $33.1 \%$ and $33.7 \%$ (in hydrated ethanol), at ageing temperatures of 60 and $23{ }^{\circ} \mathrm{C}$, respectively. In these cases, the $T_{m}$ values remained in the range of $184-188^{\circ} \mathrm{C}$. DSC results showed that the $X_{c}$ increases caused by ageing in ethanol were usually more intense at $60{ }^{\circ} \mathrm{C}$ than at $23{ }^{\circ} \mathrm{C}$, indicating that the temperature affects the ageing mechanism, although the fluid alone also changes the material crystallinity. For the thermal ageing experiments, it was also observed an $X_{c}$ increase, as showed by results from DSC and WAXD. The PA-11 samples aged at $60{ }^{\circ} \mathrm{C}$ showed crystallinity increase from DSC of $13.7 \%$ and $36.9 \%$ after 1 and 3 months, respectively. Because the ageing temperature is higher than $T_{g}\left(13.6^{\circ} \mathrm{C}\right.$, as shown in Figure 3$)$, the process was similar to an annealing treatment, favoring the rearrangement of the amorphous phase chains, thus contributing to crystal growth and additional crystallization. Therefore, the PA-11 is susceptible to both, fluid and temperature effects.

Because the grade of PA-11 used in the present study contains plasticizers ${ }^{23,25}$, two simultaneous processes with different kinetics seem to be operating during ageing, the removal of the plasticizer to the environment and anhydrous and hydrated ethanol absorption by the polymer. The removal of the plasticizer was confirmed by thermogravimetric analyses, shown below, and the absorption of fluid was confirmed by a volume variation evaluation (see subsection 3.4). The swelling of the material by fluid absorption and its interaction with the polymer structure caused changes in the crystallinity even at room temperature because the $T_{\mathrm{g}}$ is below $23{ }^{\circ} \mathrm{C}$. When the temperature was raised to $60{ }^{\circ} \mathrm{C}$, the effect was even more accentuated, resulting in a material with greater crystallinity degree. 
Hydrolysis could also cause an increase in crystallinity but was not considered the main cause in this process due to the low temperature employed and because the effect of the anhydrous ethanol was more drastic than that of the hydrated. Nevertheless, despite the low ageing temperature $\left(60^{\circ} \mathrm{C}\right)$, even a minor percentage of hydrolysis occurred may have led to decreases in the molar mass of PA-11, and thus, contributing to $X_{c}$ increases verified.

\subsection{TGA measurements}

The thermal scans of the PEEK and PA-11 were carried out to evaluate the thermal stability of the polymers. For PA-11, the goal was to analyze the main polymer chain degradation, as well as the loss of plasticizer. To this end, the initial plasticizer content and the remaining amount after ageing in anhydrous and hydrated ethanol at 1 and 3 months were quantified by TGA analysis.

As shown in Figure 7a, this grade of PEEK does not contain plasticizer and has a high thermal stability, which is attributed to the strong stability of the aromatic backbone, as discussed in the work of Patel et al. ${ }^{15}$. It can be seen in the thermograms of the Figure $7 \mathrm{a}$ that the main chain decomposition of the PEEK occurred in only one step, with maximum degradation temperature $\left(T_{d}\right)$ of approximately $590{ }^{\circ} \mathrm{C}$. A weight loss of $23 \%$ was observed at this temperature, resulting in the volatilization of approximately $45-50 \%$ of the polymer mass. The remaining polymer mass is supposed to be carbonaceous char. The behavior was similar in aged and unaged materials, suggesting no significant changes in thermal stability.

Figure $7 \mathrm{~b}$ shows that the decomposition of the PA-11 occurred in two main steps, with important differences in the thermal stability of the aged and unaged materials. It can be noted that the first weight loss step of the unaged PA-11 occurred at approximately $232{ }^{\circ} \mathrm{C}$ with a $6.7 \%$ mass loss. Based on the literature ${ }^{25,40,41}$, this decomposition temperature is compatible with the $N$-butyl-benzenesulfonamide (BBSA) plasticizer usually found in the composition of the PA-11. After the ageing in ethanol at $60^{\circ} \mathrm{C}$, the peaks decomposition temperature of the supposed plasticizer decreases to $182^{\circ} \mathrm{C}$ (mass loss of $3.5 \%$ after 1 month in anhydrous ethanol), $189^{\circ} \mathrm{C}$ (mass loss of $5.8 \%$ after 1 month in hydrated ethanol), $192{ }^{\circ} \mathrm{C}$ (mass loss of $5.3 \%$ after 3 months in anhydrous ethanol) and $189{ }^{\circ} \mathrm{C}$ (mass loss of $2.9 \%$ after 3 months in hydrated ethanol). This result confirmed the presence of the plasticizer in this PA-11 composition and its loss during the ageing process.

However, an opposite comportment occurred in the thermal stability of the second step degradation, corresponding to the degradation of the main chain of the PA-11, where the

Table 2. Elastic modulus $\left(E_{y}\right)$ and yield stress $\left(\sigma_{y}\right)$ of the PEEK and PA-11 obtained from tensile tests.

\begin{tabular}{|c|c|c|c|c|}
\hline Sample & Ethanol $\left(60^{\circ} \mathrm{C}\right)$ & Ageing time (days) & $E_{y}(\mathrm{GPa})$ & Yield stress $\left(\sigma_{y}\right)(\mathrm{MPa})$ \\
\hline \multirow{5}{*}{ PEEK } & Unaged & Zero & $3.44 \pm 0.17(4.94)$ & $97.55 \pm 0.35(0.36)$ \\
\hline & Anhydrous & 30 & $3.40 \pm 0.07(2.06)$ & $97.94 \pm 0.37(0.38)$ \\
\hline & Anhydrous & 90 & $3.49 \pm 0.08(2.29)$ & $97.41 \pm 0.57(0.58)$ \\
\hline & Hydrated & 30 & $3.35 \pm 0.06(1.79)$ & $95.05 \pm 0.75(0.79)$ \\
\hline & Hydrated & 90 & $3.46 \pm 0.07(2.02)$ & $95.27 \pm 0.19(0.20)$ \\
\hline Sample & Ethanol $\left(60^{\circ} \mathrm{C}\right)$ & Ageing time (days) & $E_{y}(\mathrm{MPa})$ & Yield stress $\left(\sigma_{y}\right)(\mathrm{MPa})$ \\
\hline \multirow{5}{*}{ PA-11 } & Unaged & Zero & $380.93 \pm 2.44(0.64)$ & $10.79 \pm 0.46(4.30)$ \\
\hline & Anhydrous & 30 & $180.97 \pm 2.31(1.28)$ & $8.44 \pm 0.14(1.66)$ \\
\hline & Anhydrous & 90 & $151.38 \pm 0.77(0.51)$ & $8.30 \pm 0.19(2.29)$ \\
\hline & Hydrated & 30 & $193.78 \pm 2.48(1.28)$ & $8.75 \pm 0.56(6.40)$ \\
\hline & Hydrated & 90 & $171.93 \pm 3.06(1.78)$ & $8.04 \pm 0.67(8.33)$ \\
\hline
\end{tabular}
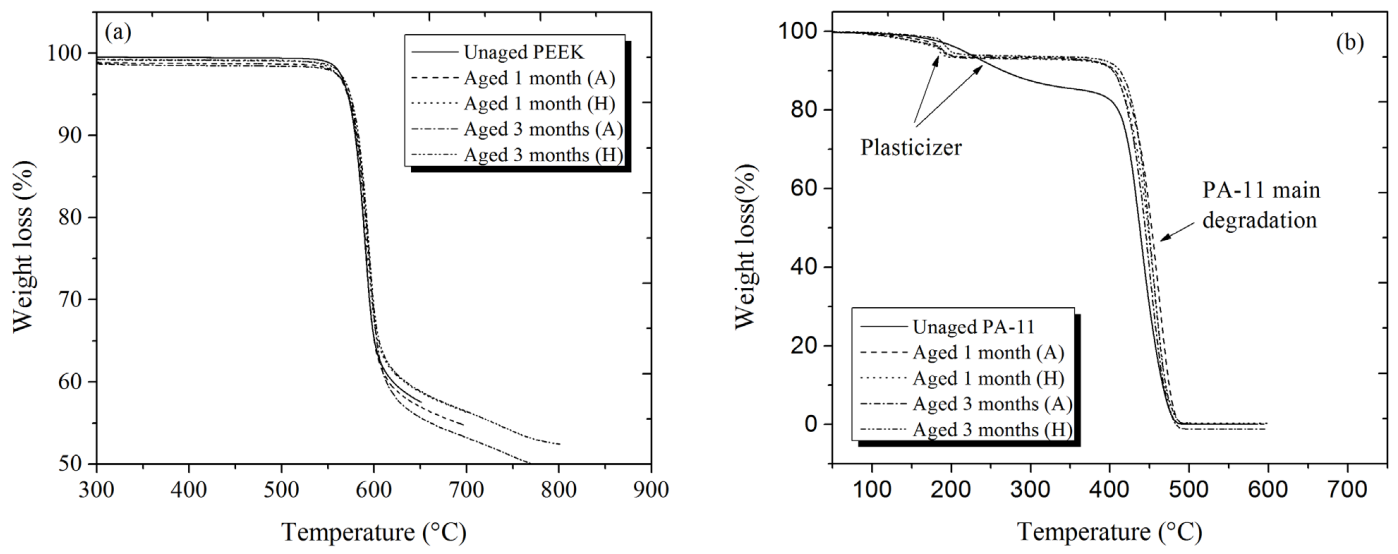

Figure 7. TGA thermograms of the PEEK (a) and PA-11 (b) unaged and aged in anhydrous (A) and hydrated (H) ethanol at $60{ }^{\circ} \mathrm{C}$ for 1 and 3 months. 
degradation temperature at this step increased as a function of the ageing time in anhydrous and hydrated ethanol at $60^{\circ} \mathrm{C}$. This is associated with the additional crystallization caused by the ageing, as discussed earlier in the WAXD and DSC analyses. Hence, the degradation temperature of the unaged PA-11 chain was $439{ }^{\circ} \mathrm{C}$, and this value was increased to the range of $449-461{ }^{\circ} \mathrm{C}$, corresponding to an increase of approximately $2-5 \%$ in the decomposition temperature of the aged samples. These results confirm the increases in the thermal stability of the main chain of the aged PA-11 relative to the unaged samples.

\subsection{Mechanical properties from tensile tests}

The uniaxial tensile curves of the PEEK and PA-11 are available in the Supplementary material (Appendix A). The tensile curves reveal high elastic modulus $\left(E_{y}\right)$ and yield stress $\left(\sigma_{y}\right)$ values for PEEK and no changes in these properties as a function of the ageing time at the established conditions. The PEEK elastic modulus was approximately 3.4 GPa, and it did not significantly change upon ageing for 1 or 3 months (Table 2), as confirmed by Student's t-tests. The elastic modulus and yield stress results confirms the high chemical and structural resistance of the PEEK to the ageing conditions employed. For PEEK at room temperature, Nguyen and Ishida ${ }^{11}$ reported an elastic modulus of $4 \mathrm{GPa}$ and yield stress of $100 \mathrm{MPa}$, and similar values also were reported in the works of Lai et al. ${ }^{37}$ and Myllari et al. ${ }^{42}$. This elevated structural stiffness observed for PEEK is typical of polymeric materials of the poly (aryl ether ketone) class. From the molecular point of view, PEEK is a polymer composed of a series of aromatic rings interspersed with two ether bonds $(\mathrm{C}-\mathrm{O}-\mathrm{C})$ and a ketone bond $(\mathrm{C}=\mathrm{O})$, both of which are naturally strong bonds ${ }^{15}$. Furthermore, each pair of aromatic rings forms a bond angle of approximately $125^{\circ 43}$, giving the chain a preferential planar zig-zag configuration, which allows a high packing degree and a good ordering of the aromatic rings, providing high thermal stability and structural stiffness to this material, as previously verified. This structure was apparently not affected by the ethanol, suggesting again that there was no effective physicochemical interaction of the PEEK polymeric chains with the ethanol. Therefore, no changes in $E_{y}$ occurred at the established ageing conditions. These results corroborated the storage modulus values $\left(E^{\prime}\right)$ obtained previously from the DMTA analyses.

On the other hand, the analysis of the tensile curves of the PA-11 indicates a low elastic modulus value of approximately $380 \mathrm{MPa}$ (shown in Table 2), as was also reported by Chaupart and Serpe $^{23}$. This low value may be partially explained by the presence of the plasticizer in PA-11, which facilitates flow and reduces the material stiffness. It is also due to its own chemical structure, basically constituted by methylene groups in a flexible chain. When unaged and aged PA-11 are compared, a significant reduction of the elastic modulus is observed, reaching levels of $52.5 \%$ and $60.3 \%$ for the material aged in anhydrous ethanol for 1 and 3 months, respectively. When the PA-11 was aged in hydrated ethanol for 1 and 3 months, the reductions were $49.1 \%$ and $54.9 \%$, respectively. In both cases, all elastic modulus mean values were significantly different in the aged materials relative to unaged PA-11, according to Student's t-tests. However, the observed PA-11 modulus reductions were not compatible with the crystallinity increases observed by the other characterization techniques (Table 1). This is attributed to the effect of the domain of the amorphous phase on the PA-11 mechanical properties, as previously explained. Additionally, the effect of hydrolysis, even in low percentage, may have affected the mechanical properties due to chain scission and consequent reduction of molecular weight, leading to elastic modulus reduction of the material. These hypotheses were corroborated below by the results of the yield stress and instrumented microindentation (subsection 3.5).

Similarly to the occurred for the elastic modulus, PEEK did not present a statistically significant difference, according to Student's t-tests between the yield stress of the unaged samples and those aged for 1 or 3 months in anhydrous ethanol, reaching a value about $97 \mathrm{MPa}$ (Table 2). However, the yield stress of the materials aged for 1 and 3 months in hydrated ethanol was slightly lower than that of the unaged sample (Table 2). The reductions observed were $2.6 \%$ and $2.3 \%$ for the materials aged for 1 and 3 months, respectively. In this case, despite the low reduction, the statistical tests indicated a significant difference, suggesting that hydrated alcohol might have a plasticizing effect on the PEEK surface, as previously detected from WAXD and DSC analyses.

On the other hand, similar to the elastic modulus, the PA-11 yield stress had a significant reduction from approximately $11 \mathrm{MPa}$ to values close to $8 \mathrm{MPa}$ after 1 and 3 months ageing in both types of ethanol (Table 2). The yield stress reductions were $21.8 \%$ and $23.1 \%$, respectively, in the materials aged for 1 and 3 months in anhydrous ethanol at $60{ }^{\circ} \mathrm{C}$, and $18.9 \%$ and $25.5 \%$, respectively in the materials aged for 1 and 3 months in hydrated ethanol at $60{ }^{\circ} \mathrm{C}$. As occurred with the elastic modulus, the behavior of the yield stress is not consistent with the degree of crystallinity observed from WAXD and DSC (see Table 1). The main justifications follow below.

Table 3 presents the values of the PA-11 volume increase caused by polymer swelling during the ageing in the different alcohols at different exposure times. These measures were obtained by Archimedes' method, as described in the literature ${ }^{44}$. The volume increments observed after 90 and 60 days were similar to those obtained after 30 and 15 days (Table 3), indicating that after a few days

Table 3. Volume increases of the PA- 11 aged in ethanol at $60^{\circ} \mathrm{C}$ as a function of the ageing time: (a) PA- 11 specimens aged in anhydrous ethanol. ${ }^{(b)}$ PA-11 specimens aged in hydrated ethanol.

\begin{tabular}{cccc}
\hline Sample & Ageing time (days) & Volume increase (\%) $^{(\mathbf{a})}$ & ${\text { Volume increase }(\%)^{(\mathbf{b})}}$ \\
\multirow{2}{*}{ PA-11 } & 15 & $7.17 \pm 0.04(0.56)$ & $6.61 \pm 0.03(0.45)$ \\
& 30 & $5.95 \pm 0.02(0.34)$ & $6.43 \pm 0.04(0.62)$ \\
& 60 & $6.03 \pm 0.01(0.16)$ & $6.45 \pm 0.02(0.31)$ \\
& 90 & $6.13 \pm 0.04(0.65)$ & $5.24 \pm 0.03(0.57)$ \\
\hline
\end{tabular}


of ageing, the polymer has already absorbed a substantial volume of anhydrous and hydrated ethanol, and this amount is maintained approximately constant for longer immersion times (saturation). The oscillations are attributed to the process of plasticizer extraction happening simultaneously with fluid absorption. Therefore, although the crystallinity increases upon ageing (Table 1), the percentage change was not significant, and the general behavior of the mechanical properties was governed by the material's amorphous phase and corresponding swelling.

In addition, it is possible that the absorbed ethanol can be associated to PA-11 chains by hydrogen bonds, exerting a plasticizer effect, thus contributing to the elastic modulus and yield stress reductions. The hypotheses proposed so far are well corroborated with the instrumented microindentation results presented below.

\subsection{Mechanical properties from instrumented microindentation tests}

Microhardness can be defined as a measure of the resistance of a material to plastic deformation. Its quantification by microindentation strongly depends on several test parameters such as the type of indenter and polymer, loading and unloading rate, holding time, and maximum test load, among others $^{33-35}$. Thus, different polymer chemical structures will have different mechanical responses, which are governed by the viscoelasticity of these materials. The instrumented Berkovich microhardness (referred from now on as $\mu-\mathrm{HB}$ ) and instrumented elastic modulus $\left(E_{i t}\right)$ of the materials were the main properties assessed. The $\mu$-HB depends on the projected contact area of the indented region $\left(A_{p}\right)$, at a specified load, whereas $E_{i t}$ is obtained from the instantaneous unloading curve and depends of the relationship with $A_{p}$ and the measured unloading stiffness ${ }^{33-35}$.

In the supplementary material (Appendix A) is available a diagram of the complete loading-holding-unloading cycle used in each indentation performed at maximum loads of 210, 310 and $410 \mathrm{mN}$. This procedure allowed assessing different indentation depths on the surface of the aged and unaged PEEK and PA-11 samples.

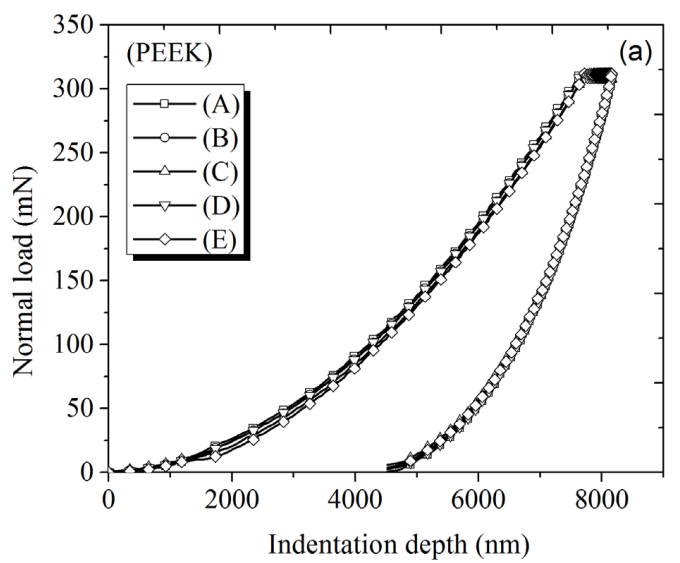

Figure 8 presents two graphs of the typical curves of applied load as a function of the indentation depth $\left(h_{\max }\right)$ using a $310 \mathrm{mN}$ maximum load for PEEK (Figure 8a) and PA-11 (Figure 8b), considering both materials in the conditions unaged and aged for 1 and 3 months in anhydrous and hydrated ethanol at $60{ }^{\circ} \mathrm{C}$. The same behavior was observed when the 210 and $410 \mathrm{mN}$ maximum loads were applied, and therefore, these curves are not presented. The loading and unloading profiles of the curves in Figure 8a show that aged PEEK did not suffer significant modifications in the maximum depth reached by the indenter, which was approximately $0.8 \times 10^{4} \mathrm{~nm}$ for both, the unaged and aged materials.

The $E_{i t}$ values of the PEEK obtained on the unloading were practically the same, approximately $3.7 \mathrm{GPa}$. These $E_{i t}$ values were in agreement with those found by Lai et al. ${ }^{37}$ and Molazemhosseini et al. ${ }^{45}$. On the other hand, Figure $8 \mathrm{~b}$ shows an increase in the maximum indentation depth obtained at PA-11 aged for 1 and 3 months, in both types of alcohol at $60{ }^{\circ} \mathrm{C}$. In this case, due to the significant amount of fluid absorbed by PA-11, the unaged material presented a $h_{\max }$ value of approximately $2.4 \times 10^{4} \mathrm{~nm}$, which was increased to approximately $2.6 \times 10^{4} \mathrm{~nm}$ (for the samples aged for 1 month in anhydrous and hydrated ethanol) and $2.8 \times 10^{4} \mathrm{~nm}$ (for the samples aged for 3 months in anhydrous and hydrated ethanol). These increases in penetration depth represent expressive $\mu-\mathrm{HB}$ and $E_{i t}$ reductions at the PA-11 samples aged at $60{ }^{\circ} \mathrm{C}$, differently from what occurred at PEEK.

The instrumented elastic modulus of the PEEK and PA-11 obtained from micro-IITs as a function of the maximum load, ageing time and type of alcohol are shown in Figure 9. The $E_{i t}$ values of the PEEK and PA-11 aged at $60{ }^{\circ} \mathrm{C}$ in an oven is also included. It can be observed that the elastic modulus of the PEEK before and after 1 and 3 months ageing in anhydrous and hydrated ethanol again shows a value of approximately $3.7 \mathrm{GPa}$. The $E_{i t}$ values of unaged/aged material are in good agreement with the literature $37,45,46$. The comparisons of the elastic modulus of unaged and aged PEEK were performed by Student's t-tests, and no significant differences were observed between the

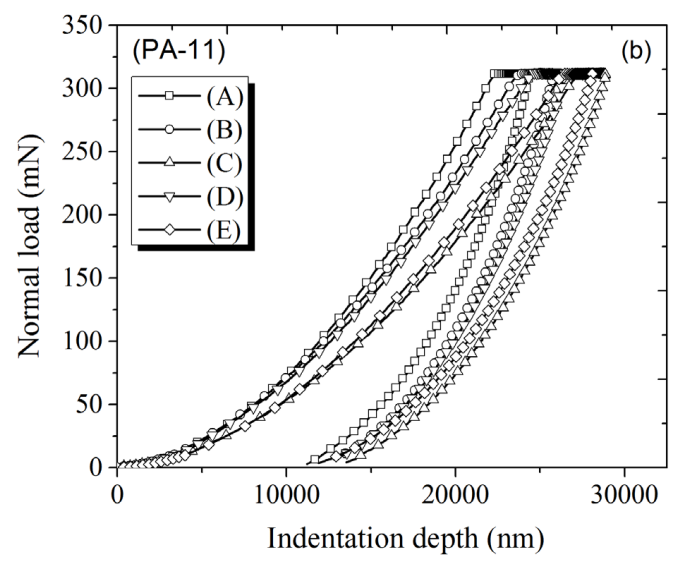

Figure 8. Loading-holding-unloading versus indentation depth at a load of $310 \mathrm{mN}$ for PEEK (a) and PA-11 (b) as a function of the ageing time: unaged materials (A), and aged at $60^{\circ} \mathrm{C}$ by 1 month in anhydrous ethanol (B), 3 months in anhydrous ethanol (C), 1 month in hydrated ethanol (D), and 3 months in hydrated ethanol (E). 


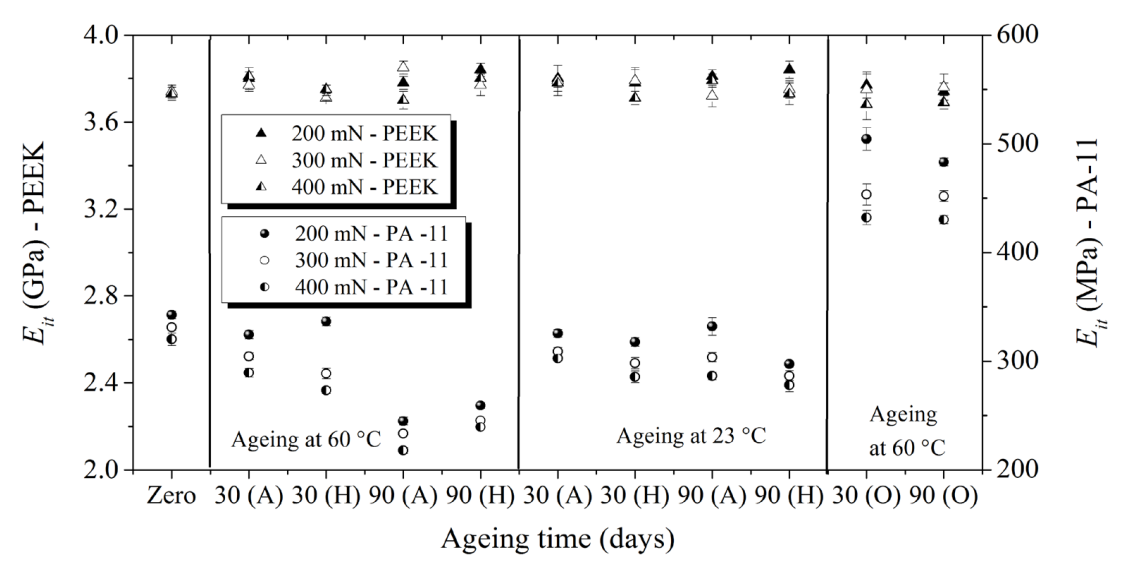

Figure 9. Behavior of the instrumented elastic modulus $\left(E_{i t}\right)$ from micro-IITs of the unaged and aged PEEK and PA-11 in anhydrous (A) and hydrated $(\mathrm{H})$ ethanol, and post-annealing in oven with hot-air $(\mathrm{O})$.

mean pairs compared. Similarly, the elastic modulus of the PEEK annealed at $60^{\circ} \mathrm{C}$ showed a value of $\sim 3.7 \mathrm{GPa}$. These results were very close to values of the modulus from DMTA and tensile tests, previously shown, again indicating the high chemical and structural resistance of the PEEK, as well as its excellent thermal stability. These results are also well correlated with the crystallinity values from Table 1 and proved that small changes in the $X_{c}$ of the PEEK post-ageing in ethanol do not affect its mechanical properties.

On the other hand, the PA-11 $E_{i t}$ values presented significant reductions (as shown in Figure 9), which were confirmed by Student's t-tests. At $310 \mathrm{mN}$ maximum load, the aged PA-11 at $60^{\circ} \mathrm{C}$ shows $E_{\text {it }}$ reductions from approximately $331 \mathrm{MPa}$ to approximately $304 \mathrm{MPa}$ (aged 1 month in anhydrous ethanol, equivalent to $8.1 \%$ reduction), $288 \mathrm{MPa}$ (aged 1 month in hydrated ethanol, equivalent to $12.9 \%$ reduction), $233 \mathrm{MPa}$ (aged 3 months in anhydrous ethanol, equivalent to $29.6 \%$ reduction) and $245 \mathrm{MPa}$ (aged 3 months in hydrated ethanol, equivalent to $25.9 \%$ reduction). The modulus decrease was progressive with ageing time, which probably occurred because of the strong chemical interaction of the PA-11 with anhydrous and hydrated ethanol, leading to this polymer swelling (Table 3 ) and reduction of the mechanical properties caused by an increase of the total free volume of the polymer chains, as previously discussed. Additionally, some percentage of hydrolysis, related in subsections 3.1 and 3.2, may have occurred, thus contributing to this $E_{i t}$ reduction verified. These results of $E_{i t}$ also are in good agreement with the tensile and DMTA properties.

Figure 9 shows that such reduction gradients after 1 month ageing of the PA-11 in anhydrous and hydrated ethanol became yet more accentuated after 3 months ageing. For PA-11 aged in anhydrous and hydrated ethanol at $23^{\circ} \mathrm{C}$, there was also an elastic modulus reduction as a function of time, as shown in Figure 9, although not so marked as for ageing at $60^{\circ} \mathrm{C}$. It can be observed that the $E_{i t}$ values obtained from PA-11 ageing at $23^{\circ} \mathrm{C}$ are located in a range intermediate between those obtained from unaged PA-11 and that aged in ethanol at $60{ }^{\circ} \mathrm{C}$ (see Figure 9). Hence, it can be perceived that the ageing temperature of $60^{\circ} \mathrm{C}$ associated with ethanol directly influences the PA-11 ageing mechanism, strongly affecting its mechanical properties.

The effect of the fluid on the material can be perceived by comparing the modulus for the materials aged at $60^{\circ} \mathrm{C}$ in ethanol and the material aged in the oven at the same temperature (Figure 9). After annealing, the PA-11 $E_{i t}$ value reached $453.3 \mathrm{MPa}$ (increase of $36.9 \%$ ) and $451.8 \mathrm{MPa}$ (increase of $36.5 \%$ ) for 1 and 3 months ageing, respectively, which can be attributed to the $X_{C}$ increases (shown in Table 1), which are associated with crystal growth and additional amorphous phase crystallization. On the other hand, the PA-11 samples aged for 1 and 3 months in the fluid experienced significant $E_{i t}$ reductions, which are correlated with chain scion and swelling effects, previously explained.

The micro-IITs of the PA-11 with maximum loads of 210 and $410 \mathrm{mN}$ showed the same tendency of reduction of the elastic modulus occurred in evaluation with $310 \mathrm{mN}$ (Figure 9). In addition, it can be noted that the mechanical properties $\left(E_{i t}\right.$ and $\left.\mu-\mathrm{HB}\right)$ were reduced with the maximum depth reached through the loads used in this test. This decay is due to the increase in the activation volume under the indenter. As reported by Oliveira et al. ${ }^{47}$, the magnitude of the volume under the indenter is crucial on the measured values of the modulus. In a viscoelastic material, the beginning of the plastic deformation is the result of chain movements located in the amorphous region (higher free volume) and is constrained by the crystalline phase, which acts as the elastic part of the system. The amorphous phase is sensitive to localized shear stresses, and as suggested by Eyring theory ${ }^{48}$, an increase in the applied stress causes a localized temperature built up reducing the local viscosity. The closer to the surface, the higher is the effect of constriction by the crystalline phase due to the smaller volume assessed.

The micro-IITs of the PEEK showed that the $\mu$-HB values had only minor variations (similarly to occurred to $E_{i t}$ ) remaining approximately $265 \mathrm{MPa}$ before and after ageing (Figure 10). In this case, the Student's t-tests did not indicate significant variations. In few cases, the small differences observed were attributed to the plasticizing effect that ethanol might have caused on the PEEK surface layers, but without 


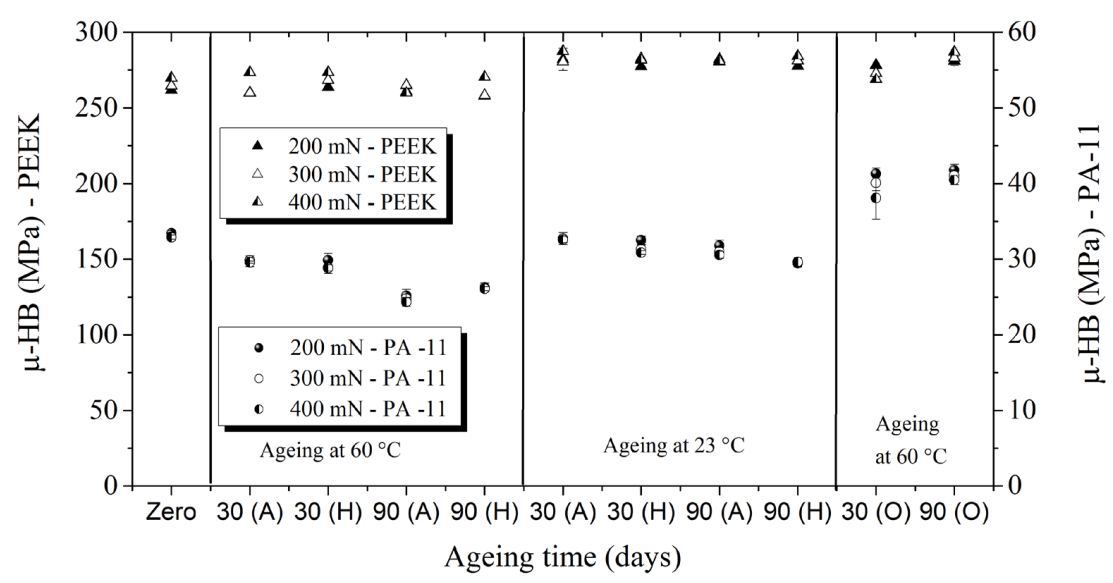

Figure 10. Behavior of the instrumented Berkovich microhardness ( $\mu$-HB) from micro-IITs of the unaged and aged PEEK and PA-11 in anhydrous (A) and hydrated $(\mathrm{H})$ ethanol, and post-annealing in oven with hot-air $(\mathrm{O})$.

a significant effect on the PEEK volumetric mechanical behavior as showed by tensile results. Comparative to the literature, the $\mu$-HB values obtained are consistent with those reported by Molazemhosseini et $\mathrm{al}^{45}$ and $\mathrm{Ji}$ et al. ${ }^{46}$.

On the other hand, the $\mu$-HB value of the unaged PA-11 was $32.9 \mathrm{MPa}$, which was reduced to approximately $29.8 \mathrm{MPa}$ (reduction of $9.4 \%$ ) and $28.8 \mathrm{MPa}$ (reduction of $12.5 \%$ ) for the materials aged for 1 month in anhydrous and hydrated ethanol at $60^{\circ} \mathrm{C}$, respectively. Meanwhile, the PA-11 aged for 3 months in anhydrous and hydrated ethanol at $60{ }^{\circ} \mathrm{C}$ showed $\mu-\mathrm{HB}$ values of $24.7 \mathrm{MPa}$ (reduction of $24.9 \%$ ) and $26.1 \mathrm{MPa}$ (reduction of $20.7 \%$ ), respectively. In this case, the statistical analysis of Student's t-tests also showed significant differences among $\mu-\mathrm{HB}$ values of the aged and unaged PA-11 samples. These reductions are correlated with chain scion and polymer swelling effects, previously mentioned.

As occurred in the analyses of the $E_{i t}$ of the PA-11 after ageing in ethanol at temperatures of 60 and $23{ }^{\circ} \mathrm{C}$, its $\mu-\mathrm{HB}$ values were distributed in a range of values between the $\mu$-HB of unaged PA-11 and that aged in ethanol at $60{ }^{\circ} \mathrm{C}$ (Figure 10). In case of the PA- 11 annealed at $60^{\circ} \mathrm{C}$, the $\mu$-HB values showed increases of $24.3 \%$ (equivalent to $40.9 \mathrm{MPa}$ ) and $24.6 \%$ (equivalent to $41.0 \mathrm{MPa}$ ) for the samples annealed for 1 and 3 months, respectively. These increases are also well correlated with the $X_{c}$ increases of Table 1, occurred due to crystal growth, as previously correlated, and explain the higher $E_{i t}$ values and again justify the effective influence of the environment on the mechanical properties of the aged PA-11.

\section{Conclusions}

PEEK showed good chemical resistance to ageing in anhydrous and hydrated ethanol and a mechanical, thermal and structural behavior apparently compatible with this fluid. WAXD and DSC results identified a small plasticizing effect of ethanol on the PEEK surface molecules, but apparently without affecting the volumetric physical-mechanical properties. The PEEK elastic modulus maintained values of approximately 3.4 and $3.7 \mathrm{GPa}$, obtained on the stress-strain and DMTA/micro-IITs, respectively. In general, the elastic modulus values obtained by these three methods were consistent for the PEEK and PA-11 polymers. The mechanical properties were also well correlated with the crystallinity degree development by samples of PEEK and PA-11 unaged and aged in ethanol $\left(60\right.$ and $\left.23{ }^{\circ} \mathrm{C}\right)$, as well as with those obtained from samples annealed at $60^{\circ} \mathrm{C}$. In view of these results, it is safe recommends the use of PEEK for ethanol fuel transport or storage.

PA-11, conversely, had a significant interaction with ethanol, leading to its swelling due to the fluid absorption by its amorphous phase. The final $E_{i t}$ and $\mu$-HB of the PA-11 were predominantly governed by this amorphous phase. After the ageing in ethanol at $60{ }^{\circ} \mathrm{C}$, a significant reduction of these mechanical properties was verified due to chemical effect, leading to loss of material performance. On the other hand, annealing purely at $60^{\circ} \mathrm{C}$ caused significant increases in $E_{i t}$ and $\mu$-HB due the crystallization of this amorphous phase. However, the influence of these $X_{c}$ increase on the mechanical properties was suppressed by the effect of the swelling. Because of the sensitivity of the PA-11 to ethanol, it was concluded that the use of this polyamide grade in ethanol transport/storage structures at temperature of $60^{\circ} \mathrm{C}$ is not indicated, though its application in this work was very helpful as a reference material for comparison with PEEK, indicating that test conditions, although very mild, can lead to important information on materials performance during the ageing evaluation of the both polymers.

\section{Acknowledgements}

The authors thank the Brazilian agencies CNPq and CAPES/MEC for financial support, and Victrex ${ }^{\circledR}$ Company for supplying the PEEK polymer. The CENPES/Petrobras is also thanked for providing the ethanol fuel. 


\section{References}

1. Jeuland N, Montagne X and Gautrot X. Potentiality of ethanol as a fuel for dedicated engine. Oil \& Gas Science and Technology. 2004; 59(6):559-570. http://dx.doi.org/10.2516/ogst:2004040.

2. Craigie LJ, Svatek MJ and White MN. Development of composite for underground gasohol storage tanks. Materials Performance. 1986; 25(9):34-40.

3. Singh R. Ethanol corrosion in pipelines. Materials Performance. 2009; 48(5):53-55.

4. Sowards JW, Williamson CH, Weeks TS, McColskey JD and Spear JR. The effect of Acetobacter sp. and a sulfate-reducing bacterial consortium from ethanol fuel environments on fatigue crack propagation in pipeline and storage tank steels. Corrosion Science. 2014; 79:128-138. http://dx.doi.org/10.1016/j. corsci.2013.10.036.

5. Yahagi Y and Mizutani Y. Corrosive wear of steel in gasolineethanol-water mixtures. Wear. 1984; 97(1):17-25. http://dx.doi. org/10.1016/0043-1648(84)90078-4.

6. Capodanno V, Petrillo E, Romano G, Russo R and Vittoria V. Effect of physical aging on the properties of films of amorphous poly (ether ether ketone) (PEEK). Journal of Applied Polymer Science. 1997; 65(13):2635-2641. http://dx.doi.org/10.1002/ (SICI)1097-4628(19970926)65:13<2635:AID-APP5>3.0.CO;2-C.

7. Moreira AR, Panossian Z, Bragagnolo GM, Santos CA, Gandur $\mathrm{MC}$ and Souza EM. Corrosividade do etanol anidro, do etanol hidratado e da mistura combustível E25 (25\% etanol/75\% gasolina). Alcoolbrás. 2010; 128:42-48.

8. Alchikh M, Fond C, Frère Y and Pelletier H. Mechanochemical degradation of poly (vinyl fluoride) by sodium hydroxide measured by microindentation. Journal of Materials Science. 2010; 45(9):2311-2316. http://dx.doi.org/10.1007/s10853-0094193-1.

9. Bakeer RM, Guice LK, Sever VF and Boyd GR. Fluid migration into lined pipelines. Tunnelling and Underground Space Technology. 2005; 20(5):452-462. http://dx.doi.org/10.1016/j. tust.2005.02.006.

10. Mohammed MH, Banks WM, Hayward D, Liggat JJ, Pethrick RA and Thomson B. Physical properties of poly (ether ether ketone) exposed to simulated severe oilfield service conditions. Polymer Degradation \& Stability. 2013; 98(6):1264-1270. http://dx.doi.org/10.1016/j.polymdegradstab.2013.02.014.

11. Nguyen HX and Ishida H. Poly (aryl-ether-ether-ketone) and its advanced composites: A review. Polymer Composites. 1987; 8(2):57-73. http://dx.doi.org/10.1002/pc.750080202.

12. Hay JN and Kemmish DJ. Environmental stress crack resistance and absorption of and low-molecular-weight penetrants by poly (aryl ether ether ketone). Polymer. 1988; 29(4):613-618. http:// dx.doi.org/10.1016/0032-3861(88)90074-2.

13. Cornélis H, Kander RG and Martin JP. Solvent-induced crystallization of amorphous poly (ether ether ketone) by acetone. Polymer. 1996; 37(20):4573-4578. http://dx.doi. org/10.1016/0032-3861(96)00246-7.

14. Osborn BN and Blundell DJ. The morphology of poly (arylether-ether-ketone). Polymer. 1983; 24(8):953-958. http:// dx.doi.org/10.1016/0032-3861(83)90144-1.

15. Patel P, Hull TR, McCabe RW, Flath D, Grasmeder J and Percy M. Mechanism of thermal decomposition of poly (ether ether ketone) (PEEK) from a review of decomposition studies. Polymer Degradation \& Stability. 2010; 95(5):709-718. http:// dx.doi.org/10.1016/j.polymdegradstab.2010.01.024.

16. Yuan M, Galloway JA, Hoffman RJ and Bhatt S. Influence of molecular weight on rheological, thermal, and mechanical properties of PEEK. Polymer Engineering \& Science. 2011; 51(1):94-102. http://dx.doi.org/10.1002/pen.21785.

17. Lu Q, Yang Z, Li X and Jin S. Synthesis, morphology, and melting behavior of poly (ether ether ketone) of different molecular weights. Journal of Applied Polymer Science. 2009; 114(4):2060-2070. http://dx.doi.org/10.1002/app.3078.

18. Krishnaswamy RK and Kalika DS. Phase behavior, crystallization, and morphology of poly (ether ether ketone)/polyarylate blends. Polymer Engineering \& Science. 1996; 36(6):786-796. http:// dx.doi.org/10.1002/pen.10466.

19. Dandy LO, Oliveux G, Wood J, Jenkins MJ and Leeke GA. Accelerated degradation of polyetheretherketone (PEEK) composite materials for recycling applications. Polymer Degradation \& Stability. 2015; 112:52-62. http://dx.doi. org/10.1016/j.polymdegradstab.2014.12.012.

20. White KL, Jin L, Ferrer N, Wong M, Bremner T and Sue HJ. Rheological and thermal behaviors of commercial poly (aryletherketone)s. Polymer Engineering \& Science. 2013; 53(3):651-661. http://dx.doi.org/10.1002/pen.23309.

21. Vasconcelos GC, Mazur RL, Ribeiro B, Botelho EC and Costa ML. Evaluation of decomposition kinetics of poly (ether-ether-ketone) by thermogravimetric analysis. Materials Research. 2014; 17(1):227-235. http://dx.doi.org/10.1590/ S1516-14392013005000202.

22. Nohara LB, Costa ML, Alves MA, Takahashi MFK, Nohara EL and Rezende MC. Processing of high performance composites based on PEEK by aqueous suspension prepregging. Materials Research. 2010; 13(2):245-252. http://dx.doi.org/10.1590/ S1516-14392010000200020.

23. Chaupart $\mathrm{N}$ and Serpe G. Relaxation-structure relationship in bulk and plasticized polyamide 11. Journal of Polymer Science. Part B, Polymer Physics. 1996; 34(14):2351-2365. http://dx.doi. org/10.1002/(SICI)1099-0488(199610)34:14<2351:AIDPOLB5>3.0.CO;2-Z.

24. Chaupart N, Serpe G and Verdu J. Molecular weight distribution and mass changes during polyamide hydrolysis. Polymer. 1998; 39(6-7):1375-1380. http://dx.doi.org/10.1016/S00323861(97)00414-X.

25. Romão W, Castro EV, Filho EAS, Guimarães RC, Silva $\mathrm{AL}$, Teixeira SC, et al. Ageing of polyamide 11 used in the manufacture of flexible piping. Journal of Applied Polymer Science. 2009; 114(3):1777-1783. http://dx.doi.org/10.1002/ app.30793.

26. American Society for Testing and Materials - ASTM. ASTM D638-10: Standard test method for tensile properties of plastics. West Conshohocken: ASTM; 2010.

27. American Society for Testing and Materials - ASTM. ASTM D5023-07 - Standard test method for measuring the dynamic mechanical properties: In flexure (three-point bending). West Conshohocken: ASTM; 2007.

28. International Organization for Standardization - ISO. ISO 175-2010: Plastics - Methods of test for the determination of the effects of immersion in liquid chemicals. London: ISO; 2010.

29. Oliveira LM, Araújo ES and Guedes SM. Gamma irradiation effects on poly (hydroxybutyrate). Polymer Degradation \& Stability. 2006; 91(9):2157-2162. http://dx.doi.org/10.1016/j. polymdegradstab.2006.01.008.

30. Gautam D, Ikram S and Gupta B. Structural characterization of alpha methyl styrene-butyl acrylate-grafted polyetheretherketone films. Journal of Applied Polymer Science. 2013; 128(5):32053212. http://dx.doi.org/10.1002/app.38507. 
31. Zhang Q, Mo Z, Liu S and Zhang H. Influence of annealing on structure of nylon 11. Macromolecules. 2000; 33(16):59996005. http://dx.doi.org/10.1021/ma000298d.

32. Menczel JD and Prime RB. Thermal analysis of polymers: fundamentals and applications. Hoboken: John Wiley \& Sons; 2009.

33. Oliver WC and Pharr GM. Measurement of hardness and elastic modulus by instrumented indentation: Advances in understanding and refinements to methodology. Journal of Materials Research. 2004; 19(1):3-20. http://dx.doi.org/10.1557/jmr.2004.19.1.3.

34. Oliver WC and Pharr GM. An improved technique for determining hardness and elastic modulus using load and displacement sensing indentation experiments. Journal of Materials Research. 1992; 7(6):1564-1583. http://dx.doi.org/10.1557/JMR.1992.1564.

35. Mencík J, He LH and Nemecek J. Characterization of viscoelasticplastic properties of solid polymers by instrumented indentation. Polymer Testing. 2011; 30(1):101-109. http://dx.doi.org/10.1016/j. polymertesting.2010.11.006.

36. Montgomery DC, Runger GC and Hubele NF. Estatística aplicada à engenharia. Rio de Janeiro: LTC; 2011.

37. Lai YH, Kuo MC, Huang JC and Chen M. On the PEEK composites reinforced by surface-modified nano-silica. Materials Science and Engineering A. 2007; 458(1-2):158-169. http:// dx.doi.org/10.1016/j.msea.2007.01.085.

38. Jolly L, Tidu A, Heizmann J-J and Bolle B. Microstructure evolution in polyamide PA11 under small uniaxial extension. Polymer. 2002; 43(25):6839-6851. http://dx.doi.org/10.1016/ S0032-3861(02)00486-X.

39. Zhang Q, Mo Z, Zhang H, Liu S and Cheng SZD. Crystal transitions of nylon 11 under drawing and annealing. Polymer. 2001; 42(13):5543-5547. http://dx.doi.org/10.1016/S00323861(01)00050-7.
40. Wypych G. Handbook of plasticizers. Toronto: ChemTec; 2012.

41. Rogalskiy S, Korzhenko A and Montanari T. An improved process for making an external plasticization of aliphatic polyamides and plasticizers useful for said plasticization. FR Patent EP 1873200-A1. 2006 June 29.

42. Myllari V, Ruoko TP and Jarvela P. The effects of UV irradiation to polyetheretherketone fibres - Characterization by different techniques. Polymer Degradation \& Stability. 2014; 109:278284. http://dx.doi.org/10.1016/j.polymdegradstab.2014.08.003.

43. Kurtz SM and Devine JN. PEEK Biomaterials in trauma, orthopedic, and spinal implants. Biomaterials. 2007; 28(32):48454869. http://dx.doi.org/10.1016/j.biomaterials.2007.07.013.

44. Mark JE. Physical properties of polymers handbook. Cincinnati: Springer-Verlag; 2007.

45. Molazemhosseini A, Tourani H, Naimi-Jamal MR and Khavandi A. Nanoindentation and nanoscratching responses of PEEK based hybrid composites reinforced with short carbon fibers and nano-silica. Polymer Testing. 2013; 32(3):525-534. http:// dx.doi.org/10.1016/j.polymertesting.2013.02.001.

46. Ji S, Yu H, Zhao J and Liang F. Comparison of mechanical property and machinability for polyetheretherketone and glass fiber-reinforced polyetheretherketone. Advances in Mechanical Engineering. 2015; 7(4):1-7. http://dx.doi. org/10.1177/1687814015578357.

47. Oliveira GL, Costa CA, Teixeira SC and Costa MF. The use of nano- and micro-instrumented indentation tests to evaluate viscoelastic behavior of poly (vinylidenefluoride) (PVDF). Polymer Testing. 2014; 34:10-16. http://dx.doi.org/10.1016/j. polymertesting.2013.12.006.

48. Ward IM and Sweeney J. Mechanical properties of solid polymers. Chichester: John Wiley \& Sons; 2013. 
Appendix A. Supplementary data

Supplementary data related to this article can be found at home page of Materials Research Ibero-american Journal of Materials (http://www.materialsresearch.org.br).
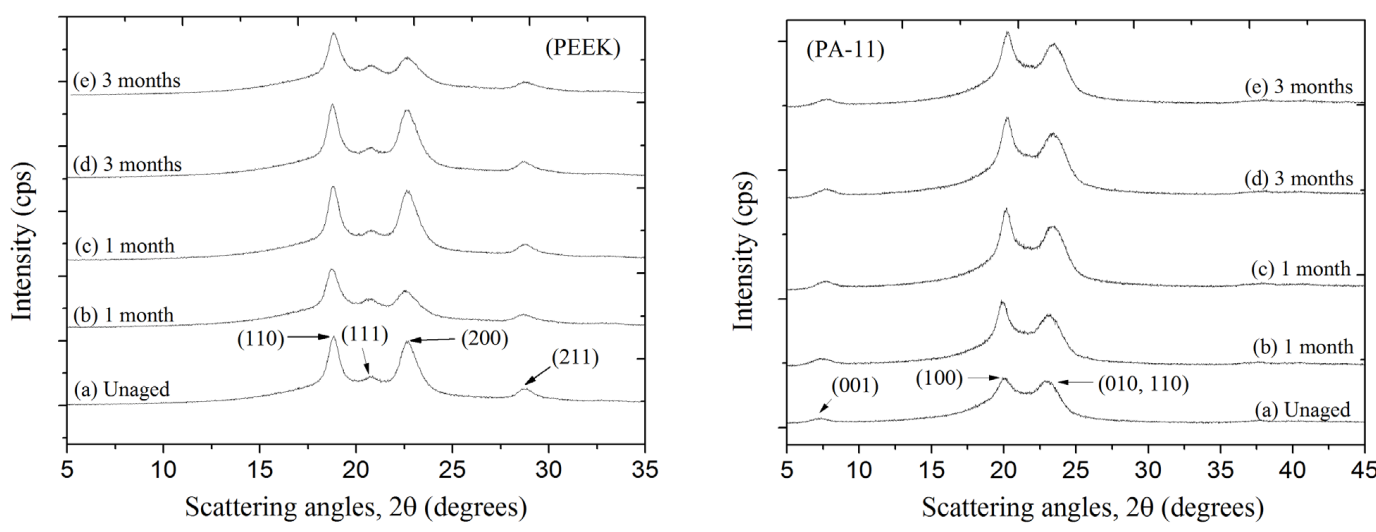

Figure 1A. X-ray diffractograms of the unaged PEEK and PA-11 (curves a) and aged at $60^{\circ} \mathrm{C}$ for 1 month in anhydrous ethanol (curves b), 1 month in hydrated ethanol (curves c), 3 months in anhydrous ethanol (curves d), and 3 months in hydrated ethanol (curves e).
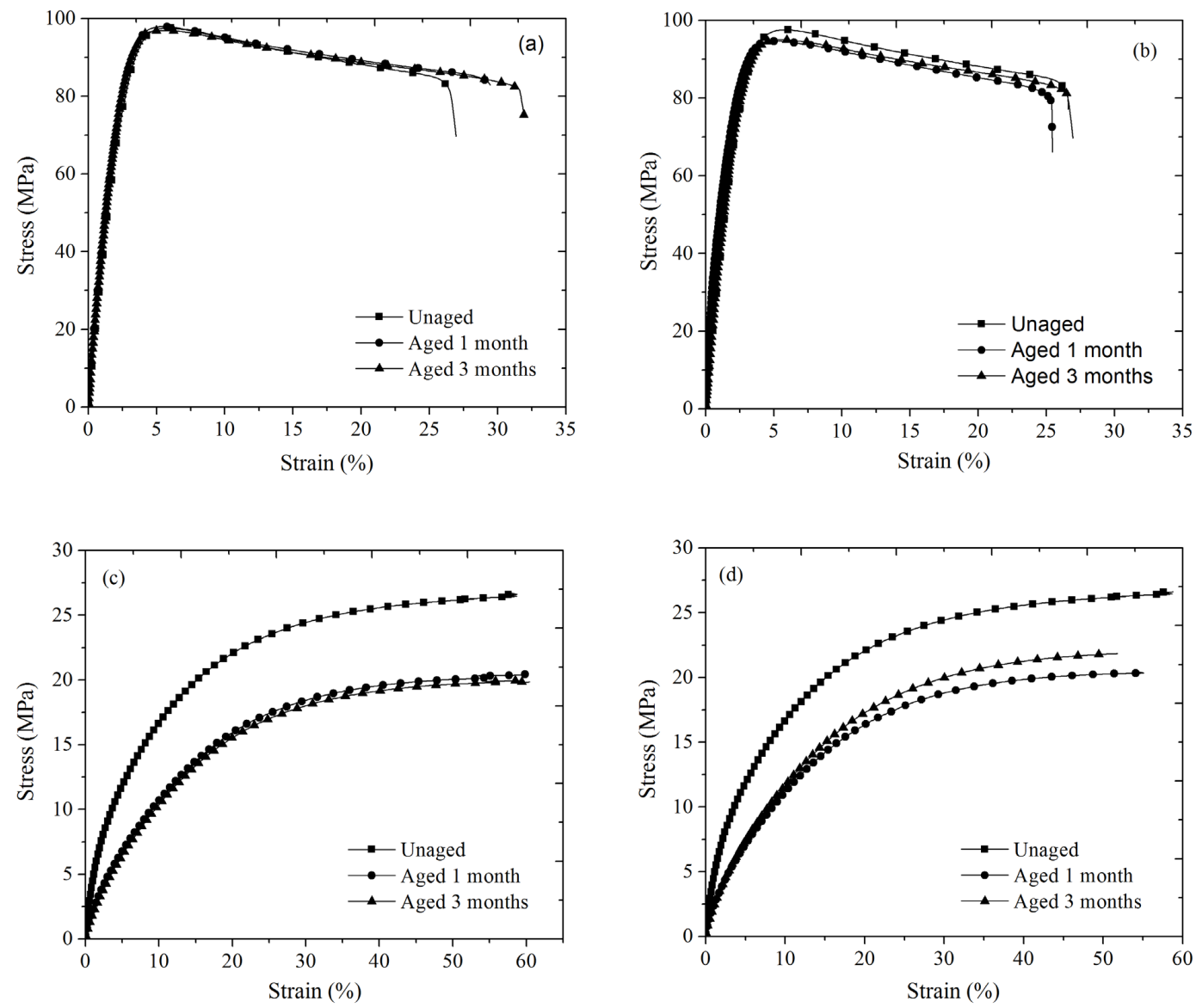

Figure 2A. Stress-strain curves of the polymers aged at $60^{\circ} \mathrm{C}$ : a) PEEK in anhydrous ethanol, b) PEEK in hydrated ethanol, c) PA-11 in anhydrous ethanol, and d) PA-11 in hydrated ethanol. 


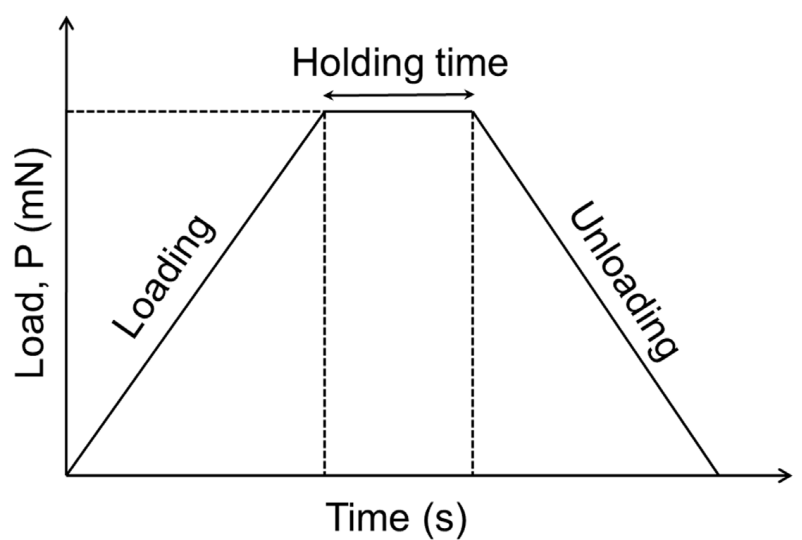

Figure 3A. General representation of a curve of load versus time with three segments during a complete loading-holding-unloading cycle. 